\title{
Physico-chemical and Functional Properties of Three Hull-less Barley (Hordeum vulgare) Varieties Grown in the High Altitude Region
}

\author{
Anju Rani*, Sangita Sood and Farhan Mohiuddin Bhat \\ ${ }^{1}$ CSKHPKV Palampur, 176062 Kangra, Himachal Pradesh, India \\ *Corresponding author
}

\section{A B S T R A C T}

\section{Keywords}

Barley varieties, Physicochemical

characteristics,

Nutritional

characteristics

Article Info

Accepted:

17 August 2020

Available Online:

10 September 2020
Three Hull-less Barley varieties viz. Dolma, BHS-352 and HBL-276 cultivated in higher altitudes of Himachal Pradesh (India) were analyzed for their physicochemical and functional characteristics. The breadth and width of the grains were found to determine the weight of the grains. Among the experimental barley varieties, Dolma variety showed the highest water absorption capacity as it contains greater amount of small granules starch as compared to others. The highest emulsion stability was obtained in $B H S-352$ barley variety due the greater adherence of protein fraction on its granules. The different parameters like moisture, ash, crude fat, protein, crude fiber, and carbohydrate content were found to be in the range of 7.91-8.97, 2.26-2.64, 2.69-3.24, 12.8-14.2, 2.26-2.81, 71.38-73.75 per cent respectively.

\section{Introduction}

Barley (Hordeum vulgare L.) is the world's fourth largest cereal grain produced after wheat, rice, and corn, which could be classified into hulled barley and hull-less barley according to the presence or absence of the husk on the grain (Mayer, 2012). The hull-less barley needs less space for storage and transportation and also results in lesser loss of vitamins and minerals during peeling operations as compared to hulled barley (Liu et al., 1996).
Approximately three-quarters of the worldwide barley production is used for animal feed, while 20 per cent is malted for use in alcoholic and non-alcoholic beverages and 5 per cent is used as a component in the production of number of food products (Blake et al., 2011).

It is available in different types viz. hulled, hull-less, normal, waxy barley as well as low and high $\beta$-glucan barley. In India, its utilization as a food crop is restricted to only the tribal areas of hills. 
Barley is also an important source of starch that constitutes about 65 to 68 per cent of the grain. Barley can grow in a wide range of environmental conditions including extremes of latitude, longitude and high altitude in comparison to any other cereal (Vangool and Vernon, 2006). Generally, Barley acts as a functional food due to its health-promoting components that have shown positive health effect such as $\beta$ - glucan. These special characteristics of barley enable its use in the formulation of various kinds of functional foods. With the changing lifestyles and increasing urbanization, diseases like coronary heart disease, diabetes, etc. are on the rise all over the world.

Changes in dietary habits are one of the effective manners suggested preventing these diseases. Besides this, in the past few years, it has been shown that inclusion of nutraceuticals such as soluble dietary fibers can help in controlling the blood cholesterol and glucose levels besides providing benefits to gut health. Barley grains possess higher amounts (3-7\%) of soluble dietary fiber called beta-glucan which helps in lowering postprandial blood glucose and the risk of cardiovascular diseases by reducing LDL cholesterol content (Behall et al., 2004).

The low incidence of hyperlipidemia and diabetes in the Tibetan population has been associated with the consumption of hull-less barley. The complex carbohydrates present in barley ensures slow release of glucose upon digestion into the bloodstreams thereby resulting in lowering glycemic index and thus essential for patients suffering from diabetes (Powell et al., 2002). After thorough scanning of literature, it is observed that hardly any research has been done to focus on the structural and functional characteristics of these traditional hull-less barley varieties grown in Himachal Pradesh. Keeping in view, the desirable health promoting attributes of hull-less barley, the present research had been focused to investigate the cumulative effects of composition and morphology on their several functional characteristics.

\section{Materials and Methods}

\section{Procurement of Materials}

Hull-less barley grains of three varieties viz Dolma, HBL-276 and BHS-352 were collected from local landeries of the Regional Research Station, Bajaura, (Tribal areas of Himachal Pradesh). The procured samples were cleaned manually for removing any kind of adhering dust, debris and foreign particles. The grains were then ground into a fine powder with the help of stainless steel mixer grinder and stored in airtight food-grade polyethylene terephthalate containers at room temperature for further analysis. The chemicals and reagents used for the analysis were used of analytical grade and analysis was carried out in triplicate to reduce error.

\section{Physical and functional characteristics of Hull-less Barley Varieties}

\section{Physical characteristics}

\section{Size (Length, Breadth and Thickness)}

The size of grains was measured in terms of length, breadth and thickness with the help of Vernier Caliper. Ten grains in triplicate were taken and length, breadth and thickness were measured.

\section{Thousand kernel weight}

Thousand grains in triplicate were selected randomly and weighed in an electrical weighing balance.

\section{Bulk density}

For estimating bulk density, the barley grains were filled in measuring cylinders up to a 
certain level from the constant height followed by weighing. The bulk density was determined by using the formula as mentioned below:-

\section{Bulk density $=$ Weight $(g) /$ Volume $(m l)$}

\section{True density}

The true density of barley grain gives the ratio of mass to the volume occupied by it and was measured by the toluene displacement method. Barley grains were weighed and put in graduated cylinder containing a known amount of toluene and rise in toluene level was noted. The true density was calculated as the ratio of the mass of the barley grains to the volume of toluene displaced by it.

$$
\text { True density }=\frac{\text { Weight }(\mathrm{g})}{\text { Volume of toluene displaced }(\mathrm{ml})}
$$

\section{Porosity}

Porosity $\left({ }^{\varepsilon}\right)$ is defined as the percentage of air between the grains as compared to a unit volume of grains, was calculated from bulk and true densities by using the following relationship described by Jain and Bal (1997).

$\varepsilon=\left(\frac{\rho_{t}-\rho_{b}}{\rho_{t}}\right) \times 100$

Where, ${ }^{\varepsilon}$, is the porosity $(\%),{ }^{\rho_{b}}$ is the bulk density $(\mathrm{kg} / \mathrm{m} 3)$ and $\rho_{t}$ is the true density (kg/m 3).

\section{Functional properties}

\section{Water and oil absorption capacity}

Water and oil absorption capacity were determined by the method described by (Adebowale el al., 2005). One gram of flour sample was mixed with $10 \mathrm{ml}$ of water/oil in the centrifuge tube which was allowed to stand at ambient temperature for 30 minutes.
The suspension was centrifuged at 3,000 rpm for 30 minutes, thereafter, the supernatant was collected in a measuring cylinder and the amount of water absorbed was calculated as the difference between the initial volume of water added to the sample and the volume of the supernatant. The same procedure was applied for determining the oil absorption capacity, wherein oil was used instead of water. The water/oil retained by the flour was computed as water/oil absorbed, i.e. $\mathrm{ml}$ water/oil absorbed per $\mathrm{g}$ of sample.

Water absorption capacity $(W A C)=$ Volume of water absorbed(m)/Weight of sample $(g)$

oil absorption capacity $(\mathrm{OAC})=$ Volume of oil absorbed ((ml))/Weight of sample(g)

\section{Emulsion Activity (EA) and Emulsion Stability (ES)}

Emulsion activity (EA) and Emulsion stability (ES) were determined by the method explained by Yasumatsu et al., (1972). An emulsion of $1 \mathrm{~g}$ flour sample, $10 \mathrm{ml}$ of water and $10 \mathrm{ml}$ soybean oil was prepared in a calibrated centrifuge tube which was then centrifuged at $2000 \times \mathrm{g}$ rpm for 10 minutes. The ratio of the height of the emulsion layer to the total height of the mixture was calculated as a percentage.

Emulsifying activity $(E A \%)=\left(\frac{\text { Height of emulsified layer }}{\text { Height of total contents in the tube }}\right) \times 100$

Emulsion stability was determined with the same method except for that emulsion in the centrifuge tube was initially heated in a water bath $\left(80^{\circ} \mathrm{C}\right)$ for 30 minutes and subsequently cooled for 15 minutes under tap water before centrifugation. Emulsion stability was calculated as

Emulsion stability $(E S \%)=\left(\frac{\text { Height of emulsified layer }}{\text { Height of total contents in the tube }}\right) \times 100$ 
Proximate chemical composition analysis of Hull-less barley

The proximate chemical composition in the test samples were determined by following the standard procedure as laid down in literature of AOAC (2010). The fat content was analyzed by means of Soxhlet extraction method, and protein content was determined by the Kjeldahl method. The ash content of the samples was estimated by means of muffle furnace operated at temperature of $550^{\circ} \mathrm{C}$.

\section{Statistical analysis}

The experiments were carried out in triplicate and the data obtained was presented as mean \pm standard deviation. The obtained data were subjected to Analysis of Variance (ANOVA) using OP stat software, for the analysis of commonly used experimental designs. The obtained data were interpreted at 5 per cent level of significance $(\mathrm{p} \leq 0.05)$.

\section{Results and Discussion}

An effort was made to evaluate varieties of hull-less barley obtained from tribal area of Himachal Pradesh, India. The results thus obtained are present under pertinent Tables.

\section{Physical parameters of hull-less barley varieties}

The physical parameters of quality evaluation of different hull-less barley varieties included length, width, breadth, thousand kernel weight, bulk density, true density, per cent porosity and specific gravity. And the data on the relevant factors have been depicted in Table 1. The average length of the test samples was analyzed with the help or vernier calliper upto the second decimal and which came out to be in the range of 7.41 to 7.82 $\mathrm{mm}$, with variety Dolma obtained the maximum length and BHS-352 least. The values for width and breadth were established as $3.17,3.10$ and $3.38 \mathrm{~mm} \mathrm{2.15,2.20}$ and 2.30 mm respectively in case of Dolma, $H B L-276$ and $B H S-352$. The variety $B H S-352$, having the lowest length showed the highest values for width and breadth. Similarly, the Dolma variety having the highest length among the analyzed varieties depicted lowest breadth. The principle dimensions including length, width and breadth play an important role in grading of seeds and in the calculation of various kinds of modeling kinetics like drying, cooling, aeration, equipment designing (Varnamkhasti et al., 2008). A glance at data indicates that the breadth and width plays an important role in determining the weight of the grain. Since maximum thousand kernel weight was found in $B H S$ 352 variety $(38.99 \mathrm{~g})$ due to its maximum width and breadth and compact filled grain. Whereas, the HBL-276 variety having the least width depicted lower value for thousand kernels weight $30.75 \mathrm{~g}$. The difference in principle dimensions of different barley varieties depends on grain development/ maturation process and agricultural practices.

Density is defined as weight per unit volume. The bulk density of Dolma, HBL-276, and $B H S-352$ was found to possess the values as $0.71,0.74$ and $0.75 \mathrm{~g} / \mathrm{ml}$ respectively. The bulk density for raw barley was found higher than the present analyzed samples as reported previously by Mariotti and collegues (2006). The void space between the hull and the caryopsis in hulled barley are filled with air which could account for its lesser bulk density than hull-less barley. The variations in results might be attributed to genetic composition and agro-climatic conditions. The bulk density plays an important role in the designing of silos and storage bins for grains (Nalladulai et al., 2002). The true density of the same samples was 1.33 in $H B L-276$ and $1.34 \mathrm{~g} / \mathrm{ml}$ in Dolma and BHS-352. True 
density has an essential role in separating cereal grains by using Pneumatic separators, as cereals differ in true densities from other unwanted materials.

The data in the same table reflects the value of porosity which obtained in the range of 43.16 to 46.41 per cent. The variation might be due to the shape and dimension of the grain. The differences in porosity values among different barley varieties might be attributed to the intrinsic characteristics of these varieties.

The thousand kernel weight of the experimental barley varieties was found to vary between $30.75 \mathrm{~g}$ to $38.99 \mathrm{~g}$. The thousand kernel weight is an important indicator of assessing the quality of grains and determines the growth and vigor of seedlings. Thousand kernel weight has been found to be determined by principle dimensions and length to width ratio of seed kernels, thus is an essential measurement indicator in crop research program (Li et al., 2004). The variety $B H S-352$ scored maximum value (38.99 g), HBL-276 showed least value 30.75 g, whereas Dolma showed the intermediate value of $38.22 \mathrm{~g}$. as presented in Table 1.

The thousand kernel weight depends upon cultivar, environmental conditions and agricultural practices. The thousand kernel weight had been found to decrease with increasing the level of processing from hulled to Hull-less barley.

The slight variation in the weight might be due to different cultivars and agro-climatic conditions under which the $B H S-352$ was grown. The width of the grain might have a positive effect on the weight as the weight increases with the increase in the width. The total starch concentration positively influenced the thousand grains weight.

\section{Functional properties}

The functional properties can be defined as the overall physicochemical behaviour of chemical composition in food systems during processing, storage and consumption. These properties can also play an important role in food product formulations as well as enhancing the nutritional value of formulated products.

\section{Water absorption capacity (WAC) and Oil absorption capacity}

The water absorption capacity for barley flour was found in the range of 2.4 to $2.7 \mathrm{ml} / \mathrm{g}$ as reported in Table 1 . The water absorption capacity could be attributed to $\beta$-glucan content in barley flour because there was a positive correlation between $\beta$ - glucan content and water absorption capacity. Vasanthan and Bhatty (1996) reported that the granule size may also influence granules hydration and swelling. The small starch granules having a higher ratio of surface area to unit weight hydrates and swell more efficiently than the large granules starch. In the present investigation, the Dolma variety showed the highest water absorption capacity as it contains greater amount of small granules starch as compared to others. The water absorption index quantifies the volume absorbed by the starch after swelling in excess water and indicates the integrity of starch in aqueous dispersion. The interaction between lipid and proteins with starch during the processing operations had a significant effect on water and oil absorption capacity (Sathe et $a l .$, 1982). The observed variations in the water and oil absorption capacity could be due to different concentration of proteins and their interaction with water and conformational properties. The oil absorption capacity was found to be maximum in $B H S$ $352(1.6 \mathrm{ml} / \mathrm{g})$, whereas the Dolma variety attained the least capacity for absorbing oil. 
The oil absorption capacity has an important role in determining the mouth-feel, texture and flavor retention capacity of food products formulated from cereal flours. The mechanism involved in oil retention capacity involves capillarity interaction and hydrophobic proteins have been found to have a significant role in the absorption of oil.

\section{Emulsion activity and stability}

Emulsions are defined as a dispersion of two (or more) immiscible liquids which are inherently thermodynamically unstable and tend to phase separate overtime via creaming, flocculation and/or coalescence. The emulsion activity and emulsion stability of barley flour are presented in Table 1. A glance at the table reveals that the emulsion activity was found highest in HBL-276 (51.35\%) and lowest in Dolma (41.85\%). The emulsion stability was found highest in BHS-352 (36.0\%) and lowest in Dolma variety (35.3\%). The greater adherence of protein fraction on the granules of BHS-352 could account for its highest emulsion stability as Proteins acts as the surface-active agents that form and stable the emulsion due to electrostatic repulsions on droplet surfaces of immiscible liquids. The emulsion stability determines the resistance of emulsion against stress that is induced mainly by the proteins.

\section{Proximate composition}

The hull-less barley grains are also analyzed for the proximate composition because the proximate composition of any cereal crop is considered essential in determining the quality of raw material for the development of product and for estimating the nutritional value and overall acceptance of developed food to the consumers as described by Moses et al., (2012). The different parameters like moisture, crude fat, crude fiber, ash, and dietary fiber content has been illustrated in
Table 2. The data reveals that the percent moisture content of barley varieties ranged as 7.91 to 8.97 amongst three varieties under study Dolma attained maximum 8.97 per cent followed by $B H S$-352 8.49 per cent and $H B L$ 276 (7.91 per cent) respectively. Moisture content is an essential component playing a major role in determining the shelf-life of cereals and the variation in moisture content among different barley varieties could be due to their genotypic variations. A slight variation could be due to the maturity of samples coupled with the agro climatic and varietal variations. Ash content gives an index to the mineral content in food material. A critical glance at the same table reveals that the ash content obtained in three different varieties viz. Dolma, $H B L-276$ and $B H S-352$ was recorded as 2.61, 2.26 and 2.64 per cent respectively. This shows that variety Dolma and BHS-352 attains almost close values for same constituent, whereas variety $H B L-276$ had slightly on the lower ebb. The present results are pretty close to the values earlier reported by Yadav et al., (2000). The ash contents of these barley were found to be in the same range as reported by Yadav, Luthra, Sood and Singh (2000). The ash content has an important role in determining the amount of essential minerals or inorganic compound phosphorus and potassium had been found to be major minerals present in barley, while the trace minerals included iron and zinc (Bhatty and Christison, 1975). Same Table also depicts the per cent fat in three different varieties. The crude fat content ranged from 3.24 to 2.69 per cent with $B H S-352$ having higher value and $H B L-276$ the lowest fat content. The variety $B H S-352$ attained the maximum (3.24 g) and Dolma minimum $(3.04 \mathrm{~g})$ per cent, whereas $H B L-276$ had the intermediate value i.e. 2.69 per cent. This significant variation might be due to the basic genetic make-up of the crop. The light falling on the surface also affects the composition and its quality characteristics. The highest 
percentage of lipids in Barley had been found to be present in Endosperm. The estimation of crude protein reflects the total nitrogenous and non nitrogenous proteins percent in the sample. The protein content was found highest in $B H S-352(14.2 \%)$ followed by HBL-276 (13.3\%) and Dolma (12.8\%). The Dolma variety was found to contain highest crude fiber $(2.81 \%)$ followed by $H B L-276$ $(2.55 \%)$ and $B H S-352(2.26 \%)$. Fibres in barley are due to varying presence of structural carbohydrates that are mainly affected by the presence or absence of hulls. The fiber in barley is high in $\beta$-glucan that has been found to possess positive health benefits by acting as hypoglycemic and hypocholesterolemic agents and thus has been recommended as an essential component in the human diet (Carpita, 1996). Carbohydrate constitute play an important role in the energy value of human diet, the carbohydrate content in the hull less barley varieties was found to be in the range of 71.38 to 73.75 per cent The $H B L-276$ variety was found to contain highest amount of carbohydrate $(73.75 \%)$ followed by Dolma (72.57\%) and BHS-352 (71.38\%). The variation in the proximal composition of the barley varieties could be attributed to differences in their genetic composition and growing environmental conditions including climatic and topographical factors (Kaur et al., 2005).

Table.1 Physical and functional characteristics of different hull less barley varieties

\begin{tabular}{|l|l|l|l|}
\hline Varieties & Dolma & HBL-276 & BHS-352 \\
\hline Length (mm) & $7.82 \pm 0.84^{\mathrm{a}}$ & $7.52 \pm 0.69^{\mathrm{b}}$ & $7.41 \pm 0.44^{\mathrm{c}}$ \\
\hline Width (mm) & $3.17 \pm 0.35^{\mathrm{b}}$ & $3.10 \pm 0.50^{\mathrm{c}}$ & $3.38 \pm 0.31^{\mathrm{a}}$ \\
\hline Breadth (mm) & $2.15 \pm 0.21^{\mathrm{c}}$ & $2.20 \pm 0.28^{\mathrm{b}}$ & $2.30 \pm 0.22^{\mathrm{a}}$ \\
\hline $\mathbf{1 0 0 0}$ Kernel weight(g) & $38.22 \pm 0.77^{\mathrm{a}}$ & $30.75 \pm 0.08^{\mathrm{b}}$ & $38.99 \pm 1.87^{\mathrm{a}}$ \\
\hline Bulk Density (g/ml) & $0.71 \pm 0.01^{\mathrm{b}}$ & $0.74 \pm 0.00^{\mathrm{a}}$ & $0.75 \pm 0.00^{\mathrm{a}}$ \\
\hline True density(g/ml) & $1.34 \pm 0.13^{\mathrm{a}}$ & $1.33 \pm 0.08^{\mathrm{a}}$ & $1.36 \pm 0.14^{\mathrm{a}}$ \\
\hline Porosity (\%) & $44.09 \pm 4.43^{\mathrm{b}}$ & $46.41 \pm 6.24^{\mathrm{a}}$ & $43.16 \pm 6.59^{\mathrm{c}}$ \\
\hline Water absorption(ml/g) & $2.7 \pm 1.41^{\mathrm{a}}$ & $2.2 \pm 0.00^{\mathrm{c}}$ & $2.4 \pm 0.00^{\mathrm{b}}$ \\
\hline Oil absorption (ml/g) & $1.4 \pm 0.00^{\mathrm{a}}$ & $1.5 \pm 0.00^{\mathrm{a}}$ & $1.6 \pm 0.00^{\mathrm{a}}$ \\
\hline Emulsion activity (\%) & $41.85 \pm 0.12^{\mathrm{c}}$ & $51.35 \pm 0.02^{\mathrm{a}}$ & $44.05 \pm 0.10^{\mathrm{b}}$ \\
\hline Emulsion stability (\%) & $35.3 \pm 0.23^{\mathrm{b}}$ & $35.5 \pm 0.29^{\mathrm{b}}$ & $36.0 \pm 0.61^{\mathrm{a}}$ \\
\hline
\end{tabular}

Values are expressed as mean \pm SD. Values with different letters superscript within the same row differ significantly $(\mathrm{P} \leq 0.05)$. 
Table.2 Proximate composition of different hull less barley varieties

\begin{tabular}{|l|l|l|l|}
\hline Varieties & Dolma & HBL-276 & BHS-352 \\
\hline Moisture(\%) & $8.97 \pm 0.01^{\mathrm{a}}$ & $7.91 \pm 0.11^{\mathrm{c}}$ & $8.49 \pm 0.40^{\mathrm{b}}$ \\
\hline Total ash(\%) & $2.61 \pm 0.00^{\mathrm{a}}$ & $2.26 \pm 0.03^{\mathrm{b}}$ & $2.64 \pm 0.02^{\mathrm{a}}$ \\
\hline Crude fat(\%) & $3.04 \pm 0.09^{\mathrm{b}}$ & $2.69 \pm 0.03^{\mathrm{c}}$ & $3.24 \pm 0.18^{\mathrm{a}}$ \\
\hline Protein content (\%) & $12.8 \pm 0.1^{\mathrm{c}}$ & $13.3 \pm 0.15^{\mathrm{b}}$ & $14.2 \pm 0.05^{\mathrm{a}}$ \\
\hline Crude fiber(\%) & $2.81 \pm 0.16^{\mathrm{a}}$ & $2.55 \pm 0.16^{\mathrm{b}}$ & $2.26 \pm 0.16^{\mathrm{c}}$ \\
\hline Dietary fiber (\%) ADF & $3.86 \pm 0.35^{\mathrm{a}}$ & $3.69 \pm 0.32^{\mathrm{b}}$ & $3.8 \pm 0.34^{\mathrm{a}}$ \\
\hline NDF & $21.62 \pm 0.43^{\mathrm{b}}$ & $20.05 \pm 0.09^{\mathrm{c}}$ & $22.66 \pm 0.80^{\mathrm{a}}$ \\
\hline Carbohydrate (\%) & $72.57 \pm 0.17^{\mathrm{b}}$ & $73.75 \pm 0.14^{\mathrm{a}}$ & $71.38 \pm 0.55^{\mathrm{c}}$ \\
\hline
\end{tabular}

Values are expressed as mean \pm SD. Values with different letters superscript within the same row differ significantly $(\mathrm{P} \leq 0.05)$.

From the aforesaid discussion it is concluded that the three selected varieties of barley differed significantly in their physicochemical, and functional properties. Among the analyzed barley samples, the Dolma variety showed the highest water absorption capacity as it contains greater amount of small granules starch as compared to others. The greater adherence of protein fraction on the granules of BHS-352 could account for its highest emulsion stability as Proteins acts as the surface-active agents that form and stable the emulsion due to electrostatic repulsions on droplet surfaces.

\section{Acknowledgment}

The authors are thankful to UGC for providing scholarship for the research and Research Station Bajaura, Kullu (Himachal Pradesh) in providing these Barley varieties for research purposes and the facilities provided by the Department of Food Science Nutrition and Technology, CSKHPKV, Palampur.
Conflict of Interest: The authors declare that they have no conflict of interest of any kind.

\section{References}

Adebowale, Y.A, Adeyemi, I.A, Oshodi, A.A (2005). Functional and physicochemical properties of flours of six mucuna species. Afr. J. Biotechnol. 4, 416-468.

Annl. Rev. Plant Physiol. Plant Mol. Biol. 47:445-476.

AOAC. (2010). Official methods of analysis. Association of Official Analytical Chemist, Washington D.C.UK.14.068, 2057

Behall, K.M, Scholfield, D.J, Hallfrisch, J. (2004) Diets containing barley significantly reduce lipid in mildly hyper cholesterolemic men and women. Am. J. Clin. Nutr. 80, 11851193.

Bhatty, R.S, Christison, G.I. (1975) Chemical composition and digestible energy of barley. Can. J. Anim. Sci, 55, 759764. 
Blake, T. Blake, V. Bowman, J. AbdelHaleem H (2011) Barley: Production, improvement and uses. UK: WileyBlackwell. Pp. 522-531.

Carpita NC (1996). Structure and biogenesis of cell walls of grasses.

Carpita, N.C. (1996) Structure and biogenesis of cell walls of grasses. Annu Rev Plant Ph ysiol Plant Mol Biol. 47, 445-476.

Foster-Powell, K., Holt, S.H, Brand-Miller, J.C. (2002) International table of glycemic index and glycemic load values. Am. J. Clin. Nutr. 76, 5-56.

Kaur, M. Sandhu, K.S. Singh, N. (2007) Comparative study of the functional, thermal and pasting properties of flours from different field pea (Pisum sativum L.) and pigeon pea (Cajanus cajan L.) cultivars. Food Chem. 104, 259-267.

Li, J. Thomson, M. McCouch, S.R. (2004) Fine mapping of a grain-weight quantitative trait locus in the pericentromeric region of rice chromosome 3. Genetics. 168, 21872195.

Liu, C.T. Wesenberg, D.M. Hunt, C.W. Branen, A.L. Robertson, L.D. Burrup, D.E. (1996) Hulless barley: A new look for barley in Idaho. University of Idaho Extension/CALS Publications and Multimedia.

Mariotti, M. Masoni, A. Ercoli, L. Arduini, I. (2006) Forage potential of winter cereal / legume intercrops in organic farming. Ital. J. Agron. 3, 403-412.
Mayer KFX (2012) A physical, genetic and functional sequence assembly of the barley genome. Nature. 491, 711-716.

Nalladulai, K. Alagusundaram, K. Gayathri, P. (2002.) Airflow resistance of paddy and its byproducts. Biosyst. Eng. 831, 67-75.

Sathe, S.K. Deshpade, S.S. Salunkhe, D.K. (1982) Functional properties of winged bean (Psophoxarpus tetragonolobus, L) proteins. J. Food Sci. 47, 503-506.

Vangool, D. and Vernon, L. (2006). Potential impacts of climate change on agricultural land use suitability: Barley. Department of Agriculture, Western Australia. Report No: 302

Varnamkhasti, M.G. Mobli, H. Jafari, A. Keyhani, A.R. Soltanabadi, M.H. Rafiee, S. Kheiralipour, K. (2008) Some physical characteristics of rough rice (Oryza sativa L.) grain. J. Cereal Sci. 47, 496-501.

Vasanthan, T., Bhatty, R.S. (1996) Physicochemical properties of small and large granule starches of waxy, regular, and high-amylose barleys. Cereal Chem. 73, 199-207.

Yadav, S.K. Luthra, Y.P. Sood, D.R. Singh, D. (2000) Carbohydrate make up of huskey barley. Starch/Starke. 52, 125128.

Yasumatsu, K. Sawada, K. Maritaka, S. Mikasi, M. Toda, J. Wada, T. Ishi, K. (1972) Whipping and emulsifying properties of soybean products. Agric. Biol. Chem. 36, 719 - 727.

\section{How to cite this article:}

Anju Rani, Sangita Sood and Farhan Mohiuddin Bhat. 2020. Physico-chemical and Functional Properties of Three Hull-less Barley (Hordeum vulgare) Varieties Grown in the High Altitude Region. Int.J.Curr.Microbiol.App.Sci. 9(09): 2069-2077. doi: https://doi.org/10.20546/ijcmas.2020.909.258 